\title{
The lower limit of the pulmonary artery index for the extracardiac Fontan circulation
}

\author{
Keiichi Itatani, MD, ${ }^{\text {acc }}$ Kagami Miyaji, MD, ${ }^{\text {a }}$ Yayoi Nakahata, MD, ${ }^{b}$ Kuniyoshi Ohara, MD, ${ }^{\text {a }}$ \\ Shinichi Takamoto, MD, ${ }^{\mathrm{c}}$ and Masahiro Ishii, $\mathrm{MD}^{\mathrm{b}}$
}

Objective: In the era of the staged Fontan operation, small pulmonary artery index $\left(<250 \mathrm{~mm}^{2} / \mathrm{m}^{2}\right)$ has not affected the early or midterm results. The lower limit of pulmonary artery index, however, has not yet been determined. We created numeric models of the Fontan circulation to investigate the lower limit of the pulmonary artery size.

\begin{abstract}
Methods: The extracardiac Fontan geometries with pulmonary artery index, ranging from 50 to $200 \mathrm{~mm}^{2} / \mathrm{m}^{2}$ with every $10-\mathrm{mm}^{2} / \mathrm{m}^{2}$ increase, were created from the postoperative angiographic data of 17 patients. The superior and inferior vena caval flow rates at rest and on 2 exercise levels $(0.5$ and $1.0 \mathrm{~W} / \mathrm{kg})$ were given by magnetic resonance imaging flow studies. Respiration-driven transient flow analysis was performed with a finite element solver. Energy loss and mean inferior vena caval pressure were obtained from the results.
\end{abstract}

Results: Energy loss and mean inferior vena caval pressure were prominently increased in small pulmonary artery index models, especially during exercise. The pulmonary artery indices sufficient for mean inferior vena caval pressure less than $17 \mathrm{~mm} \mathrm{Hg}$ were $80 \mathrm{~mm}^{2} / \mathrm{m}^{2}$ at rest, $100 \mathrm{~mm}^{2} / \mathrm{m}^{2}$ during $0.5-\mathrm{W} / \mathrm{kg}$ exercise, and $110 \mathrm{~mm}^{2} / \mathrm{m}^{2}$ during $1.0-\mathrm{W} / \mathrm{kg}$ exercise. With the increase of pulmonary arterial resistance, mean inferior vena caval pressure increased, but the flow pattern did not change.

Conclusions: A small pulmonary artery causes a high pressure gradient and a high energy loss. The lower limit of pulmonary artery index, considering the exercise tolerance, was $110 \mathrm{~mm}^{2} / \mathrm{m}^{2}$. (J Thorac Cardiovasc Surg 2011;142:127-35)

The Fontan operation is the definitive procedure for patients with univentricular hearts. Since its first description in 1971, many modifications have been introduced, including the intra-atrial tunnel or the fenestrated Fontan procedure. ${ }^{1,2}$ The total cavopulmonary connection, including the extracardiac Fontan operation, has several theoretic advantages relative to other types of Fontan procedures, such as lower frequencies of atrial arrhythmias and technical ease of the procedure. ${ }^{2}$ The extracardiac Fontan operation has also been proved to provide optimal hemodynamic performance in midterm outcomes. ${ }^{2}$

The pulmonary vascular bed has been considered to be one of the important criteria for the indication of the Fontan operation. ${ }^{1,3,4}$ Recently, there have been a few reports that values of the pulmonary artery index (PAI) or Nakata index ${ }^{2}<250 \mathrm{~mm}^{2} / \mathrm{m}^{2}$ do not affect the early or midterm results. ${ }^{5-7}$ Extremely small pulmonary artery size, however, may cause high central venous pressure and reduced

\footnotetext{
From the Departments of Cardiovascular Surgery ${ }^{\mathrm{a}}$ and Pediatrics, ${ }^{\mathrm{b}}$ Kitasato University School of Medicine, Sagamihara, Japan; and the Department of Cardiac Surgery, ${ }^{\mathrm{c}}$ The University of Tokyo, Graduate School of Medicine, Tokyo, Japan. Disclosures: Authors have nothing to disclose with regard to commercial support. Received for publication Dec 22, 2009; revisions received July 22, 2010; accepted for publication Nov 25, 2010; available ahead of print Jan 31, 2011.

Address for reprints: Kagami Miyaji, MD, Kitasato University, School of Medicine, Department of Thoracic and Cardiovascular Surgery, Kitasato 1-15-1, Sagamihara, Kanagawa 228-8555, Japan (E-mail: Kagami111@aol.com). $0022-5223 / \$ 36.00$

Copyright (c) 2011 by The American Association for Thoracic Surgery doi:10.1016/j.jtcvs.2010.11.033
}

exercise tolerance in response to a large pressure drop between the central vein and the pulmonary artery. It has not yet been determined whether such small pulmonary size increases the risks associated with the Fontan operation. Moreover, a lower limit of the pulmonary artery size has not yet been determined.

To reveal the hemodynamic detail and energetic efficiency of the Fontan circulation, computational fluid dynamics (CFD) models of the Fontan circulation have been reported. ${ }^{8-19}$ Because the fundamental Fontan physiology is a dissociation of the venous return from a ventricular power source, most of the previous numeric models have assumed that pulmonary blood flow is steady and continuous. ${ }^{8-17}$ Clinical observations, however, have proved that the pulmonary blood flow in the Fontan physiology is mostly dependent on the respiratory motion, ${ }^{20,21}$ often referred to as the "respiratory pump," 20,21 indicating that pulmonary blood flow is sucked into the lung during inspiration. In the Fontan circulation, decreased exercise capacity is one of the significant morbidities, and detailed studies have been reported with regard to flow dynamics of the superior vena cava (SVC) and the inferior vena cava (IVC) of patients with the Fontan circulation at rest and during exercise in relation to respiratory flow fluctuation. ${ }^{20,21}$ These studies demonstrated that flow augmentation to the pulmonary arteries with inspiration has important physiologic effects. ${ }^{2}$

We created numeric models of the extracardiac Fontan operation with respiratory fluctuating boundary conditions 


$$
\begin{aligned}
& \text { Abbreviations and Acronyms } \\
& \text { BSA }=\text { body surface area } \\
& \text { CFD }=\text { computational fluid dynamics } \\
& \text { IVC }=\text { inferior vena cava } \\
& \text { MRI }=\text { magnetic resonance imaging } \\
& \text { PAI }=\text { pulmonary artery index } \\
& \text { Rp }=\text { pulmonary arterial resistance } \\
& \text { SVC }=\text { computational fluid dynamics }
\end{aligned}
$$

on the basis of the exercise tolerance and pulmonary arterial resistance (Rp). This study was designed to reveal the lower limit of PAI for the acceptable extracardiac Fontan circulation by applying these models.

\section{MATERIALS AND METHODS Anatomic Data}

The angiographic data of 17 patients who underwent the extracardiac Fontan operation in our hospital were used to create a 3-dimensional ideal extracardiac Fontan geometry. We performed routine cardiac catheterization at 1 year after the Fontan operation. Catheter examination was performed after parental informed consent had been obtained.

While creating that geometry, we excluded patients who had the diagnosis of apicocaval juxtaposition and those who underwent a bilateral bidirectional Glenn shunt before undergoing the Fontan operation, because these subgroups have different geometric characteristics, such as conduit curvature, and may have different flow structures from those of other patients undergoing Fontan operations. The mean age of included patients was $36.0 \pm 32.0$ months, and their mean body surface area (BSA) was $0.53 \pm 0.16 \mathrm{~m}^{2}$.

The following were determined from their angiographic data: the SVC diameter, the IVC diameter, the length of the right pulmonary artery (the distance from the center of the SVC anastomosis to the first branch of the right pulmonary artery), the length of the left pulmonary artery (the distance from the center of the SVC anastomosis to the first branch of the left pulmonary artery), the length of conduit, and the conduit axis deviation between the level of the center of the conduit and the level of the IVC (Figure 1, A). The diameter of the IVC was evaluated at the level above the hepatic venous connection. We defined the diameters of the bilateral pulmonary arteries as being identical, because our patients had only slight differences in size between the right and left pulmonary arteries (the diameter of the right pulmonary artery was $9.71 \pm 2.69 \mathrm{~mm}$, whereas that of left was $9.55 \pm 1.79 \mathrm{~mm}$ ). The pulmonary artery diameters were varied to yield PAIs ranging from $50 \mathrm{~mm}^{2} / \mathrm{m}^{2}$ to $150 \mathrm{~mm}^{2} / \mathrm{m}^{2}$ with every $10-\mathrm{mm}^{2} / \mathrm{m}^{2}$ increase and PAI $200 \mathrm{~mm}^{2} / \mathrm{m}^{2}$, and the mean value of the right and left pulmonary artery sizes of 17 patients was $9.6 \mathrm{~mm}$ (equivalent to PAI $273.0 \mathrm{~mm}^{2} / \mathrm{m}^{2}$ ). The patients' PAIs were measured from the diameter of the bilateral pulmonary arteries at the site of the first branch obtained from the catheter data.

We hypothesized that conduits are anastomosed to the pulmonary artery at a site $1 \mathrm{SVC}$ radius distant from the center of the Glenn anastomosis. According to various previous numeric studies of the Fontan circulation, this design is optimal to minimize both energy loss and right and left pulmonary blood flow split. ${ }^{9-11}$ We hypothesized that the anteroposterior axes of the SVC and IVC were identical, because they were of the typical shape as in the extracardiac Fontan operation detected by the lateral views of the angiographic studies. The conduit size was determined to be $16 \mathrm{~mm}$ and connected smoothly to the IVC and pulmonary artery, because our previous numeric results revealed that a $16-\mathrm{mm}$ conduit was optimal in terms of energy loss and flow stagnation. ${ }^{19}$

\section{Computational Simulation}

Three-dimensional geometries were divided into tetrahedral computational meshes. The details of the computational simulation methodology were described in our previous article. ${ }^{19}$ Mesh density was varied to according to the vascular diameter to have the same number of mesh layers even in small pulmonary arteries, whereas the mesh quality was validated by the parameter "EquiAngle Skew," defined as $\max \left[\left(\theta_{\max }-60\right) / 120,\left(60-\theta_{\min }\right) /\right.$ 60], in which $\theta_{\max }$ and $\theta_{\min }$ are the maximum and minimum angles, respectively, between the edges of the element. We created a mesh so that all elements fit the criterion that the skewness did not exceed 0.85 . Nonsteady, transient simulations with respiratory fluctuation were performed by the backward Euler method. The finite element solver package FIDAP8.7.4 (Fluent Asia Pacific, Tokyo, Japan) was used to solve the Navier-Stokes equation of incompressible Newtonian fluid with the following blood properties: density $\rho$ of $1060 \mathrm{~kg} / \mathrm{m}^{3}$ and viscosity $\mu$ of $4.0 \times 10^{-3} \mathrm{~kg} /(\mathrm{m} \mathrm{s})$. Convergence criterion for the velocity at each time step was $10^{-4}$ times the residual, and convergence criteria for the conjugate residual and conjugate gradient squared system were both $10^{-6}$ times the residual.

\section{Boundary Conditions}

Respiration-driven, time-varying functions of boundary conditions were given for boundary conditions. Inflow boundary conditions for the SVC and IVC were given as flow velocity conditions. Mean flow rates in the SVC and IVC at rest and at 2 exercise levels $(0.5 \mathrm{~W} / \mathrm{kg}$ and $1.0 \mathrm{~W} /$ $\mathrm{kg}$ ) from magnetic resonance imaging (MRI) measurements were as given by Hjortdal and colleagues. ${ }^{21}$ We created time-varying functions in such a way that the mean respiratory flow values were used as baseline values, and we defined triangularly shaped functions up to and down to inspiration and expiration, respectively (Figure 1,B).

Outflow boundary conditions for bilateral pulmonary arteries were assumed as pressure conditions of 11,14 , and $16 \mathrm{~mm} \mathrm{Hg}$, which dropped down to $20 \%$ only at the inspiratory phase (Figure $1, B$ ). These pressure levels were equivalent to the $\mathrm{Rp}$ values of 1.2, 2.0, and 2.6 unit square meter $\left(\mathrm{Um}^{2}\right)$, respectively, if we assume the static atrial pressure to be $5 \mathrm{~mm} \mathrm{Hg}$ and calculate the $\mathrm{Rp}$ from the mean pulmonary flow and pressure drop between the pulmonary arterial pressure and static atrial pressure. Rp was scaled according to the BSA with the following formula: $\mathrm{Rp}($ scaled $)=$ pressure drop/flow $\times$ BSA. We set no extension of the outlet boundaries, because we were afraid that the extension would overestimate the effect of the small pulmonary arterial size because of the pressure loss inside the extended boundaries. The wall was assumed to be rigid, and the boundary condition was defined as a nonslip condition of zero velocity.

\section{Energy Loss and Mean IVC Pressure}

To evaluate the flow efficiency, we used two parameters: energy loss and mean IVC pressure. The formula of energy loss was justified by previous investigators. ${ }^{8-19}$

$$
\dot{\mathrm{E}}=-\int_{\text {surface }}\left(\frac{1}{2} \rho|\vec{u}|^{2}+\mathrm{P}\right) u_{i} n_{i} d S
$$

Where $\vec{u}$ (ui) describes the 3-dimentional velocity vector of a fluid, $P$ describes the static pressure of the fluid, and $\rho$ describes the density of the blood. The integral is the surface integral of the boundary surfaces and $n_{i}$ describes the vector normal to the surfaces.

In practice, total energy loss is the sum of the inlet and outlet was defined as follows:

$$
\dot{E}_{\text {loss }}=\dot{E}_{S V C}+\dot{E}_{I V C}-\dot{E}_{r P A}-\dot{E}_{l P A}
$$

Also, we calculated the mean IVC pressure of 1 respiratory cycle on each PAI model as well as that on each boundary condition. 


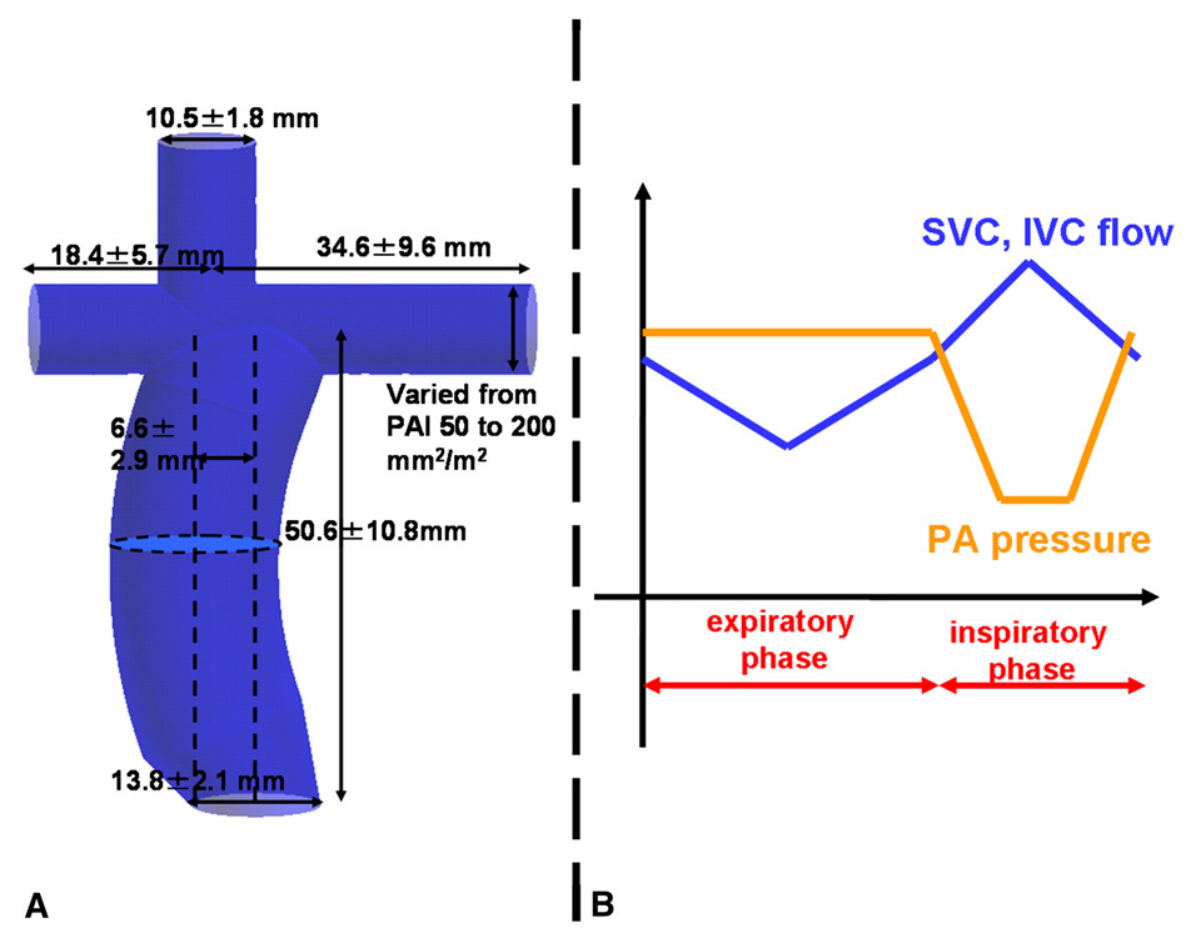

FIGURE 1. A, Geometry of extracardiac Fontan operation. Mean values of 17 patients were used to create geometry. Right and left pulmonary arteries were assumed to be same diameter and varied so that pulmonary artery index (PAI, Nakata index) ranged from $50 \mathrm{~mm}^{2} / \mathrm{m}^{2}$ to $200 \mathrm{~mm}^{2} / \mathrm{m}^{2}$ with every $10-\mathrm{mm}^{2} / \mathrm{m}^{2}$ increase. Average values of bilateral pulmonary artery $(P A)$ diameters were used, with 9.6-mm diameter equivalent to pulmonary artery index (Nakata index) of 273. Radius of conduits was $16 \mathrm{~mm}$. Conduits were anastomosed to pulmonary artery at a distance equal to 1 superior vena cava (SVC) radius from center of Glenn anastomosis site. Conduit curve was determined as though middle level of conduit deviated $6.6 \mathrm{~mm}$ from axis of inferior vena cava (IVC). B., Time varying function of boundary conditions. Superior and inferior vena caval flows were given in previously reported magnetic resonance imaging flow study. ${ }^{12}$ Pressures of bilateral pulmonary arteries were given so that pulmonary arterial resistances were 1.2, 2.0, and $2.6 \mathrm{Um}^{2}$.

\section{RESULTS}

The results are shown in color (Figures 2 and 4), illustrating the flow velocity fields of each model. The direction of each arrows indicates flow direction, and the color indicates the flow velocity magnitude. The pressure distributions for each model are also shown in color contours (Figure 3).

\section{Flow and Pressure at Rest, at $\mathrm{Rp}$ of $1.2 \mathrm{Um}^{2}$, in Each PAI Model}

At rest, extremely accelerated flows in the pulmonary arteries and just proximal to pulmonary arteries were detected in the $80-\mathrm{mm}^{2} / \mathrm{m}^{2}$ PAI model in both the expiratory and inspiratory phases (Figure 2). In the $120-\mathrm{mm}^{2} / \mathrm{m}^{2}$ PAI model, flow acceleration in the pulmonary arteries was relaxed in the expiratory phase, but the flow was still accelerated in the inspiratory phase (Figure 2). As the PAI increased, the flow acceleration in the pulmonary artery relaxed in both the expiratory and inspiratory phases (Figure 2).

The pressure drop between the conduit and the pulmonary arteries increased in the smaller pulmonary arteries. In the $50-\mathrm{mm}^{2} / \mathrm{m}^{2}$ PAI model, central venous pressure was extremely high in both the expiratory and inspiratory phases (Figure 3). In the inspiratory phase, the venous blood flow increased and the pulmonary arterial pressure decreased. As the PAI increased, at first, the pressure drop decreased more in the expiratory phase than in the inspiratory phase; as the PAI increased even further, however, the pressure drop decreased more in the inspiratory phase than in the expiratory phase (Figure 3).

\section{Flow and Pressure During Exercise}

During exercise, IVC flow rate and flow fluctuation both increase, ${ }^{21}$ and in our model conduit flow was increased relative to the conduit flow velocity at rest, as shown in Figure 4 . Accelerated flow in the pulmonary artery was detected in both the expiratory and inspiratory phases, even in the $150-\mathrm{mm}^{2} / \mathrm{m}^{2}$ PAI model. Mean IVC pressure and energy loss elevated this flow acceleration relative to values at rest.

\section{Flow and Pressure at High Rp Values at Rest}

With the increase of Rp, mean IVC pressure and pressure in the whole geometries increased. Energy loss and the flow pattern, however, did not change. 


\section{Flow at Rest at Rp $1.2 \mathrm{Um}^{2}$}
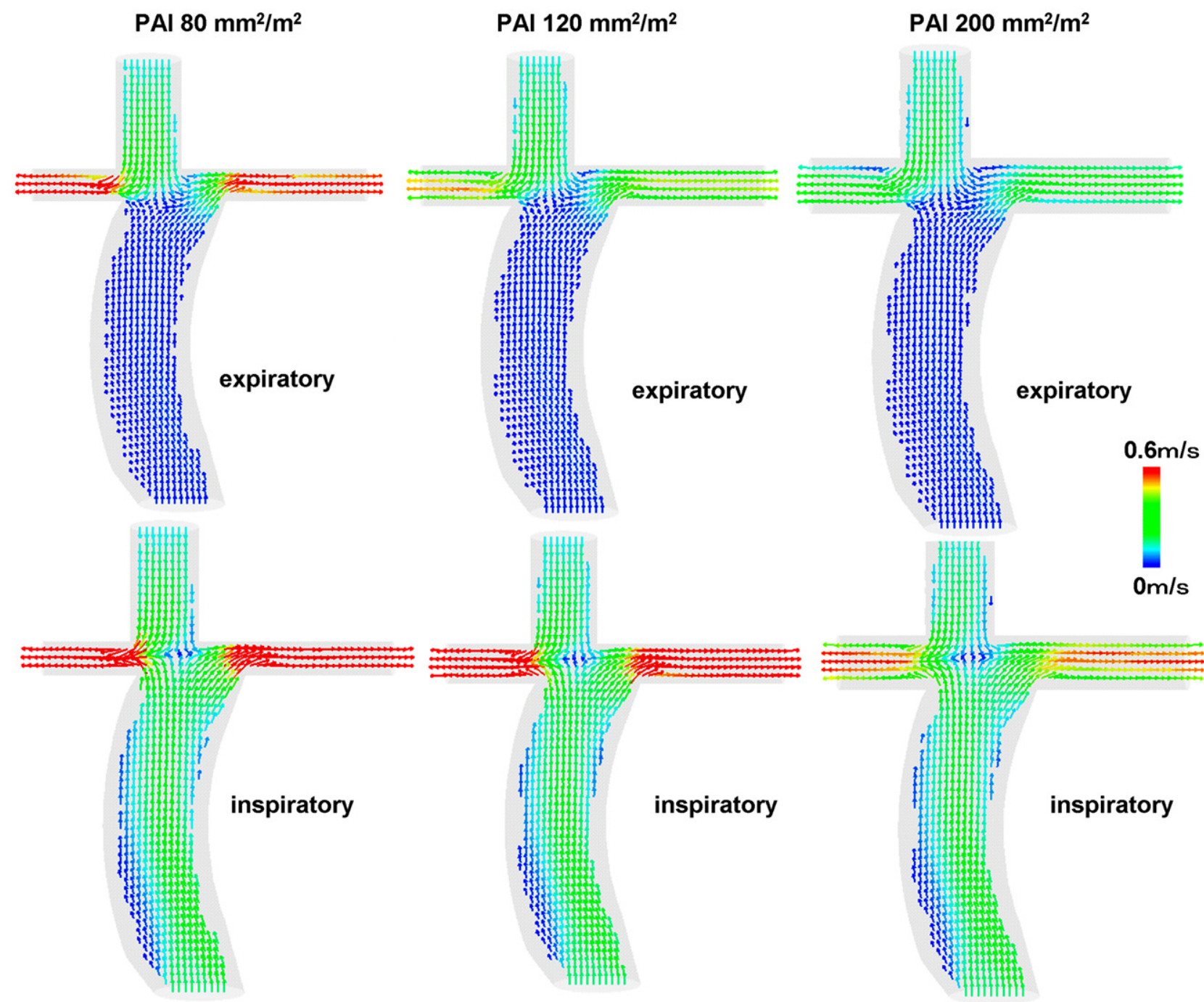

FIGURE 2. Flow features of pulmonary artery index (PAI) model areas at rest at pulmonary arterial resistance (Rp) of $1.2 \mathrm{Um}^{2}$. Direction of arrows indicates flow direction, and colors indicate flow velocity magnitudes. Flow acceleration was detected in small models with small pulmonary artery index in both expiratory and inspiratory phases.

\section{The Lower PAI Limit}

Energy loss prominently increased as the pulmonary artery size decreased. Also, just like energy loss, the mean IVC pressure increased as the pulmonary artery size decreased (Figure 5). Energy loss and mean IVC pressure prominently increased as the exercise level increased, especially in small PAI models (Figure 5, $A$ and $B$ ). The models with a mean IVC pressure greater than $17 \mathrm{~mm} \mathrm{Hg}$ expended much larger energy than those with a pressure less than $17 \mathrm{~mm} \mathrm{Hg}$.

We cut off the limit for the acceptable Fontan circulation with the mean IVC pressure at $17 \mathrm{~mm} \mathrm{Hg}$. The PAIs sufficient for the mean IVC pressure less than $17 \mathrm{~mm} \mathrm{Hg}$ at Rp of $1.2 \mathrm{Um}^{2}$ were $80 \mathrm{~mm}^{2} / \mathrm{m}^{2}$ at rest, $100 \mathrm{~mm}^{2} / \mathrm{m}^{2}$ during the $0.5-\mathrm{W} / \mathrm{kg}$ exercise, and $110 \mathrm{~mm}^{2} / \mathrm{m}^{2}$ during the $1.0-\mathrm{W} / \mathrm{kg}$ exercise. The PAIs sufficient for the mean IVC pressure less than $17 \mathrm{~mm} \mathrm{Hg}$ at rest were $80 \mathrm{~mm}^{2} / \mathrm{m}^{2}$ at $\mathrm{Rp}$ of $1.2 \mathrm{Um}^{2}, 90 \mathrm{~mm}^{2} / \mathrm{m}^{2}$ at $\mathrm{Rp}$ of $2.0 \mathrm{Um}^{2}$, and $100 \mathrm{~mm}^{2} / \mathrm{m}^{2}$ at $\mathrm{Rp}$ of $2.6 \mathrm{Um}^{2}$ (Figure 5, $C$ ).

\section{DISCUSSION}

Small pulmonary arteries have been considered a contraindication to the Fontan operation since the first report in 1971. ${ }^{1}$ Criteria for the pulmonary artery size for the successful Fontan operation were established subsequently. Nakata and associates ${ }^{3}$ defined the PAI (Nakata index) as the crosssectional area of the right and left pulmonary arteries divided by the BSA and determined the chief criterion for the indication of the Fontan operation as a PAI greater than $250 \mathrm{~mm}^{2} / \mathrm{m}^{2}$. Fontan and colleagues ${ }^{4}$ have defined 


\section{Pressure Distribution at Rest at $\mathrm{Rp} 1.2 \mathrm{Um}^{2}$}

\section{PAI $50 \mathrm{~mm}^{2} / \mathrm{m}^{2} \quad$ PAI $70 \mathrm{~mm}^{2} / \mathrm{m}^{2} \quad$ PAl $90 \mathrm{~mm}^{2} / \mathrm{m}^{2} \quad$ PAI $110 \mathrm{~mm}^{2} / \mathrm{m}^{2}$}
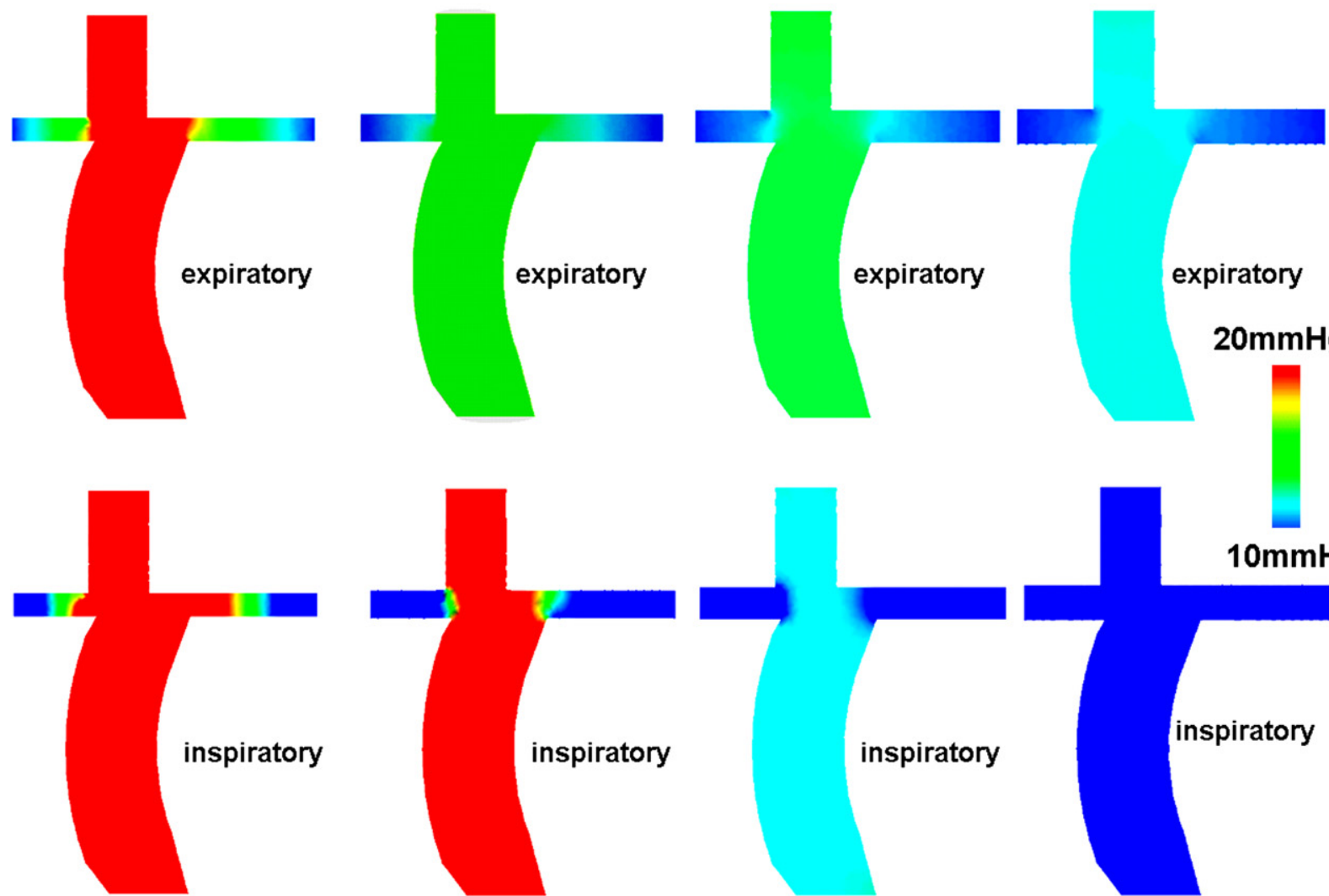

$20 \mathrm{mmHg}$

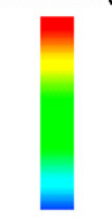

$10 \mathrm{mmHg}$

FIGURE 3. Pressure distributions at rest at pulmonary arterial resistance $(R p)$ of $1.2 \mathrm{Um}^{2}$. Pressure gradients are demonstrated with color gradients. Central venous pressures were prominently high in models with small pulmonary artery index (PAI) in both expiratory and inspiratory phases.

a McGoon ratio of 1.8 or greater, which is equivalent to PAI of at least $200 \mathrm{~mm}^{2} / \mathrm{m}^{2}$, as the necessary criterion for the indication of the Fontan operation. In the wake of many improvements in surgical strategies and perioperative management, however, several investigators ${ }^{5-7}$ have reported no significant differences in mortality between patients with PAI values greater than $250 \mathrm{~mm}^{2} / \mathrm{m}^{2}$ and those with PAI values less than $250 \mathrm{~mm}^{2} / \mathrm{m}^{2}$. In these reports, the smallest PAI in survivors was $48 \mathrm{~mm}^{2} / \mathrm{m}^{2}$, reported by Brides and coworkers ${ }^{5}$ (the second smallest PAI in that investigation, $68 \mathrm{~mm}^{2} / \mathrm{m}^{2}$, was among the nonsurvivors), while PAIs of $188 \mathrm{~mm}^{2} / \mathrm{m}^{2}$ and $104 \mathrm{~mm}^{2} / \mathrm{m}^{2}$ were reported by Girod and colleagues ${ }^{6}$ and Adachi and associates, ${ }^{7}$ respectively. According to Brides and coworkers, ${ }^{5}$ patients with small pulmonary arteries underwent complete pulmonary artery augmentation from the central pulmonary artery to the right and left pulmonary upper lobe branches with homograft patches. ${ }^{5}$ On the basis of clinical evidence, the midterm results of patients with PAI values smaller than $100 \mathrm{~mm}^{2} / \mathrm{m}^{2}$ remain unknown as reported in the literature.
In this study, our concern was the lower limit of the pulmonary artery size for successful extracardiac Fontan circulation considering the exercise tolerance. Because clinical cases of extremely small pulmonary arteries are not frequent (the smallest PAI among our 17 patients was $136 \mathrm{~mm}^{2} / \mathrm{m}^{2}$ ), we created a theoretic model to determine the lower limit and to reveal the details of flow and pressure distributions. The essential Fontan physiology is not a continuous steady pulmonary blood flow but rather a respiration-driven, nonsteady flow, referred to as a "respiratory pump." ${ }^{20,21}$ For the evaluation of exercise tolerance of patients with the Fontan circulation, respiratory flow fluctuation plays an essential role. ${ }^{20,21}$ Respiratory pump function increases during exercise, and the increase of total flow and flow fluctuation during exercise is more prominent in IVC flow than in SVC flow. ${ }^{19,21}$ Our results also revealed that the energy loss increased nonlinearly as the pulmonary artery size decreased, and the pressure drop increased, especially during exercise. Our respiratory fluctuating models revealed the mechanisms of Fontan circulatory collapse in pulmonary arteries that were too 


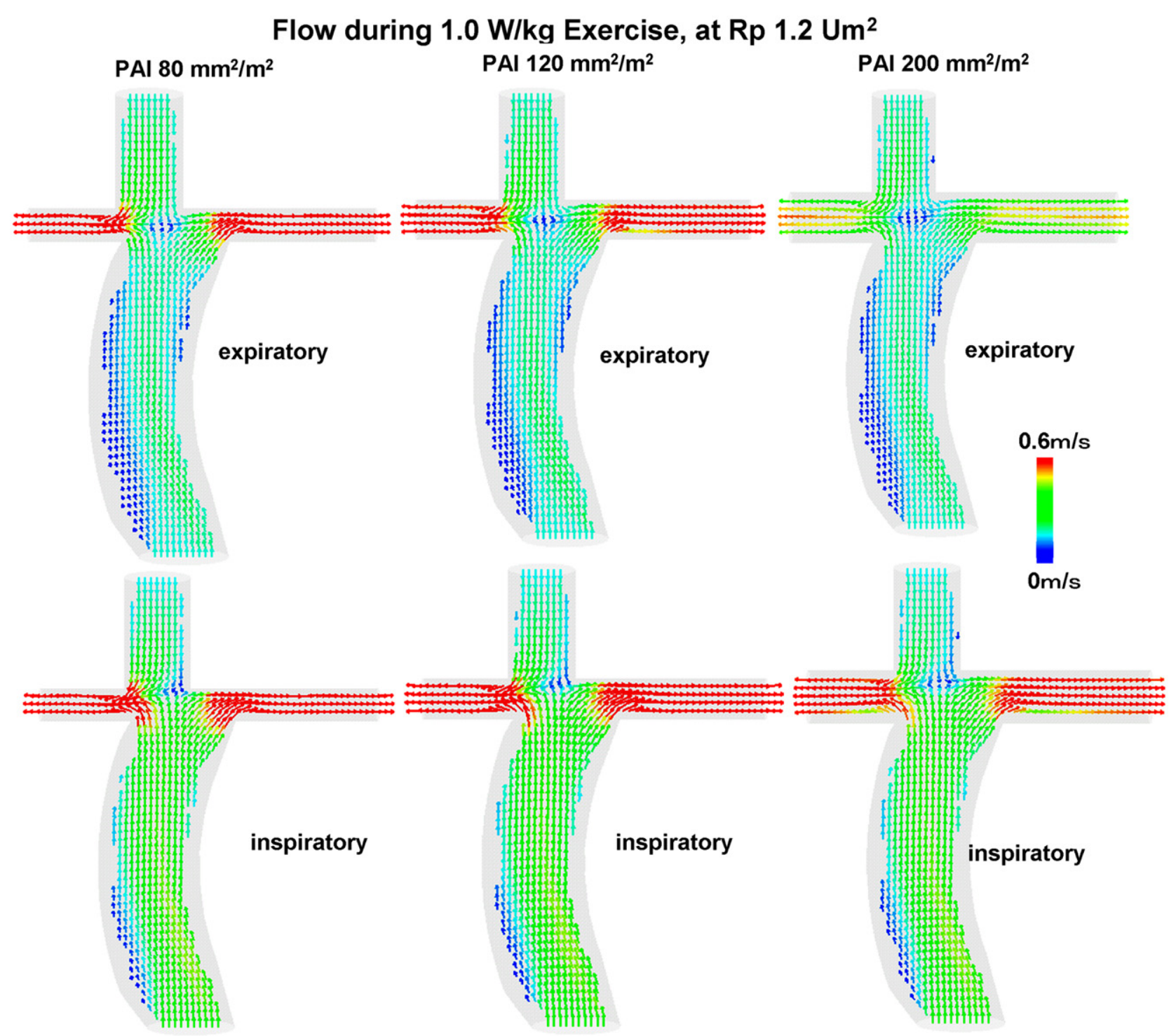

FIGURE 4. Flow features of pulmonary artery index $(P A I)$ model areas during $1.0-\mathrm{W} / \mathrm{kg}$ exercise at pulmonary arterial resistance $(R p)$ of $1.2 \mathrm{Um}{ }^{2}$. Inferior vena caval flow was increased. Flow acceleration was more prominent during exercise than in models at rest, especially in models with small pulmonary artery index, in both expiratory and inspiratory phases.

small. As PAI decreased, venous pressure during the inspiratory phase overcame that during expiratory phase (Figure 3). Results of pressure distribution during rest at $\mathrm{Rp}$ of $1.2 \mathrm{Um}^{2}$ (Figure 3) revealed that pulmonary arteries with a PAI smaller than $70 \mathrm{~mm}^{2} / \mathrm{m}^{2}$ acted as the resistant vessels, and the effects of IVC flow increase were more prominent than those of pulmonary pressure decrease, resulting in a high pressure increase. On the other hand, in pulmonary arteries with a PAI greater than $90 \mathrm{~mm}^{2} / \mathrm{m}^{2}$, the pressure spread to the central veins.

Considering the form of the equation 1 and the fact that the Fontan circulation is a low-pressure and slow-flow system, energy loss could depend on pressure more than on flow conflict or flow velocity variances. Pressure drop in a small vascular space might dissipate a great deal of energy in this calculation method, as Pekkan and colleagues ${ }^{15}$ have previously reported. This concept may be supported by the previous numeric studies by de Leval and coworkers ${ }^{9}$ and Bove and colleagues, ${ }^{12}$ which proved that patch augmentation in the Fontan anastomosis site reduced energy loss. High energy expenditure could influence the long-term results. ${ }^{8}$ From our calculations, we determined that in pulmonary arteries smaller than the lower limit of $110 \mathrm{~mm}^{2} / \mathrm{m}^{2}$, the Fontan circulation would collapse as a result of the high energy loss and high pressure drop.

Recently reported CFD models have reconstructed patient-specific 3-dimensional geometries from MRI or computed tomography to increase simulation accuracy. ${ }^{8-19}$ 

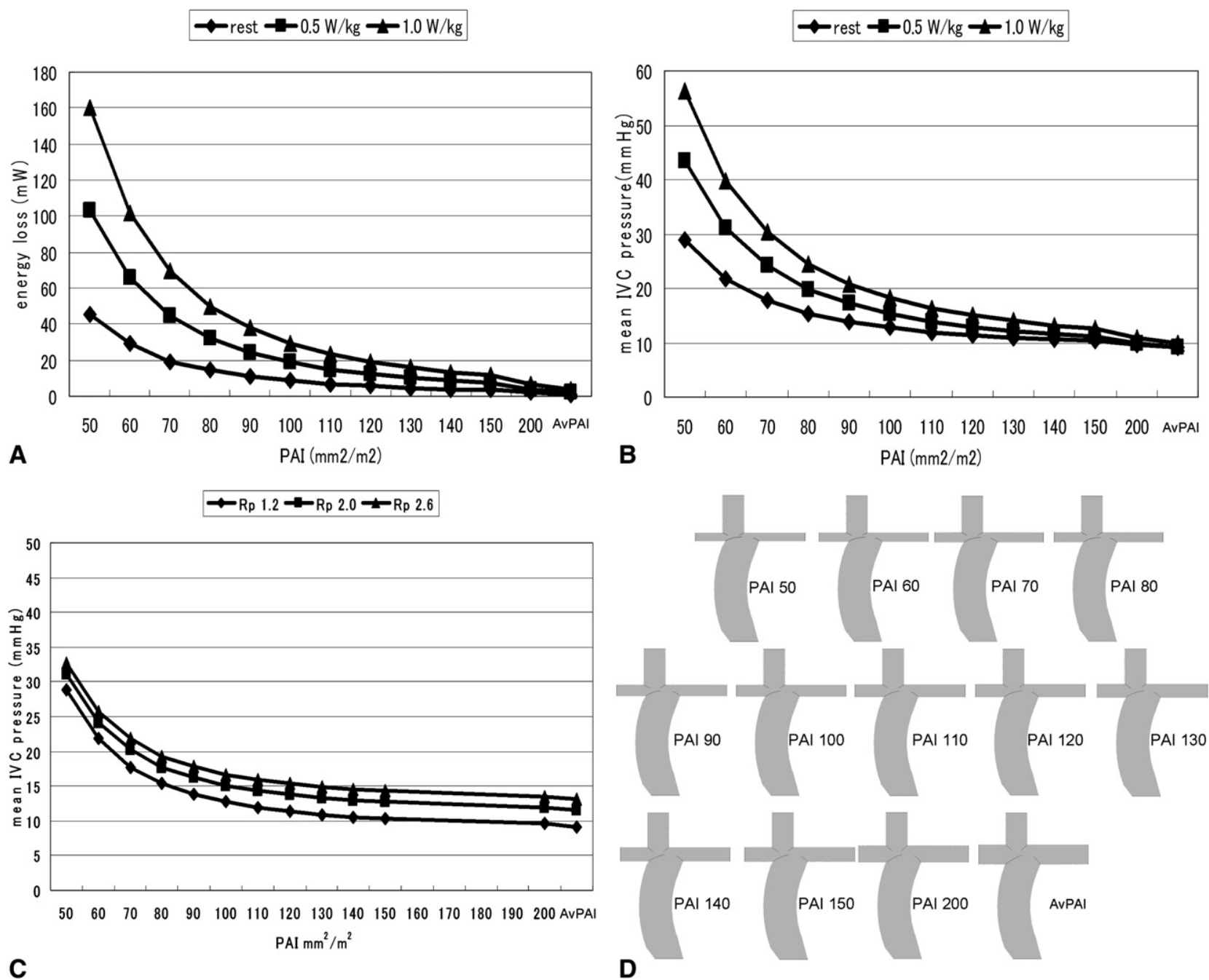

FIGURE 5. Energy loss and mean inferior vena caval $(I V C)$ pressure on various pulmonary artery index (PAI) models under various boundary conditions. $A v P A I$ indicates average pulmonary artery index of the 17 patients with Fontan circulations in our hospital. A, Energy loss and pulmonary artery index at rest and on 2 exercise levels. B, Mean inferior vena caval pressure and pulmonary arterial index at rest and on 2 exercise levels. C, Mean inferior vena caval pressure and pulmonary artery index at 3 pulmonary arterial resistance $(R p)$ levels. D, Sketches of all model geometries with different pulmonary artery indices.

We did not use a patient-specific model in this study, because our objective was to acquire the essential or empirical knowledge, such as the indications for or the strategies of the Fontan operation, and an idealized geometry has advantages in this type of study that would allow us to make general conclusions or set general guidelines for surgeons. ${ }^{15,19}$ In our study, the problem of the offset between the SVC and the conduit and the problem of the left and right pulmonary flow split were not investigated, because we consider these problems to have been adequately discussed. ${ }^{9,10,11,14}$

There have been several theoretic models mentioning the Fontan circulation with small pulmonary arteries. ${ }^{22-24}$ Models considering the effects of respiration, however, have not previously been reported. Senzaki and coworkers 22 reported that the impedance abruptly increased when the PAI was less than $100 \mathrm{~mm}^{2} / \mathrm{m}^{2}$. In their model, the basic harmonic frequency in the Fourier series expansion was defined as the frequency of the heartbeat, which was much higher than the respiration frequency. Dasi and coworkers ${ }^{23}$ revealed the relationships between the energy loss and the stenotic pulmonary arteries. Their model depends on the CFD calculations of continuous steady flow simulations. ${ }^{23}$ Their derived energy loss pulmonary artery size curve was located left of that revealed in our results, however, because their pulmonary artery size was not a PAI itself but a locally stenotic minimal diameter of the pulmonary artery. ${ }^{23}$

With respect to the inlet boundary conditions, we adopted the previously reported MRI flow study data. ${ }^{6}$ The ages of the patients studied in that report were older than those in our model. Flow data of young patients (2- or 3-year-old patients) after the Fontan operation during exercise were not available. In our study, the given boundary flow data were 
therefore corrected with the BSA. The flow ratios of the SVC and IVC were in good agreement with those in the clinical studies in the patients of these ages ${ }^{24}$ and with the inlet boundary flow ratios of the previous CFD models. ${ }^{8-19}$

With respect to the outlet boundary conditions, we adopted direct pressure boundary conditions rather than resistant boundary conditions. ${ }^{9,10,12,19}$ We chose not to adopt the resistant boundary conditions because pulmonary arterial pressure would increase during the flow-increasing inspiratory phase in resistant boundary conditions combined with lumped parameter models ${ }^{25}$ and because this could not describe the physiologic flow augmentation to the pulmonary artery during the pressure-decreasing inspiratory phase.

In numeric models, several assumptions may oversimplify the multifactor system and become study limitations. We did not consider the effect of fenestration or pulmonary artery plasty, which would naturally change the flow fields. The indication of PAI could change with successful pulmonary artery plasty or fenestration. The effects of these additional procedures therefore warrant further study. Moreover, PAI itself did not always reflect the maturity of the pulmonary capillaries or capillary volume, which is essential for a successful Fontan circulation. The catheter measurements of PAI we ordinarily use in our clinical practice have some margin of error, leading to limitations of this study. In creating the models, we assumed for convenience that the bilateral pulmonary arteries have the same diameter; in actual clinical situations, however, some patients have stenosis around the central pulmonary artery or an imbalance in pulmonary artery size between right and left. In the boundary conditions, only respiratory fluctuations were considered, but actual flow patterns of the Fontan circulation contain pulsatile fluctuations that would make the flow character more complex. Also, we did not simulate other types of Fontan operation, such as the lateral tunnel Fontan or the atriopulmonary connection. These types of Fontan operation should be handled or calculated separately, because they involve the compliant and contracting atrial wall. ${ }^{8}$ We also assumed the vessel wall to be rigid. We did not know the effect of compliances of the pulmonary arteries or the compressive effects of the conduit during the respiratory cycle. In this study, we used the geometries only with 16-mm conduits, and different conduit sizes would have an effect on the pressure distributions and energy loss increase. Our idealized geometries also had rather sharp and nonsmooth anastomosis sites that were different from the actual clinical geometries. The definition of smoothing in computational geometries would be difficult to formulate and was thus another limitation of our study caused by using idealized geometries. Pulmonary microcirculation or papillary maturity, which is thought to be essential for the Fontan circulation and to have a large impact on the Rp, cannot be considered in this study that used pressure outlet boundary conditions. Nor in this study could we cal- culate the energy expenditure in the pulmonary microcirculations. Further studies are therefore warranted to determine whether these simplifications are acceptable.

\section{CONCLUSIONS}

In the Fontan circulation, diminutive pulmonary arteries cause a high pressure gradient between the pulmonary arteries and the conduits, resulting in a high energy loss. Our study revealed that the lower limit of the PAI for a successful Fontan operation, considering the exercise tolerance, was $110 \mathrm{~mm}^{2} / \mathrm{m}^{2}$.

\section{References}

1. Fontan F, Baudet E. Surgical repair of tricuspid atresia. Thorax. 1971;26:240-8.

2. Lee C, Lee CH, Hwang SW, Lim HG, Kim SJ, Lee JY, et al. Midterm follow-up of the status of Gore-Tex graft after extracardiac conduit Fontan procedure. Eur J Cardiothorac Surg. 2007;31:1008-12.

3. Nakata S, Imai Y, Takanashi Y, Kurosawa H, Tezuka K, Nakazawa M, et al. A new method for the quantitative standardization of cross-sectional areas of the pulmonary arteries in congenital heart diseases with decreased pulmonary blood flow. J Thorac Cardiovasc Surg. 1984;88:610-9.

4. Fontan F, Fernandez G, Costa F, Naftel DC, Tritto F, Blackstone EH, et al. The size of the pulmonary arteries and the results of the Fontan operation. J Thorac Cardiovasc Surg. 1989;98:711-24.

5. Bridges ND, Farrell PE Jr, Pigott JD 3rd, NorwoodWI, Chin AJ. Pulmonary artery index. A nonpredictor of operative survival in patients undergoing modified Fontan repair. Circulation. 1989;80(3 Pt 1):I216-21.

6. Girod DA, Rice MJ, Mair DD, Julsrud PR, Puga FJ, Danielson GK. Relationship of pulmonary artery size to mortality in patients undergoing the Fontan operation. Circulation. 1985;72(3 Pt 2):II93-6.

7. Adachi I, Yagihara T, Kagisaki K, Hagino I, Ishizaka T, Kobayashi J, et al. Preoperative small pulmonary artery did not affect the midterm results of Fontan operation. Euro J Cardiothorac Surg. 2007;32:156-62.

8. Van Haesdonck JM, Mertens L, Sizaire R, Montas G, Prunode B, Daenen W, et al. Comparison by computerized numeric modeling of energy losses in different Fontan connections. Circulation. 1995;92(9 Suppl):II322-6.

9. de Leval MR, Dubini G, Migliavacca F, Jalali H, Camporini G, Redington A, et al. Use of computational fluid dynamics in the design of surgical procedures: application to the study of competitive flows in cavo-pulmonary connections. J Thorac Cardiovasc Surg. 1996;111:502-13.

10. Dubini G, de Leval MR, Pietrabissa R, Montevecchi FM, Fumero R. A numerical fluid mechanical study of repaired congenital heart defects. Application to the total cavopulmonary connection. J Biomech. 1996;29:111-21.

11. Khunatorn Y, Mahalingam S, DeGroff CG, Shandas R. Influence of connection geometry and SVC-IVC flow rate ratio on flow structures within the total cavopulmonary connection: a numerical study. J Biomech Eng. 2002;124:364-77.

12. Bove EL, de Leval MR, Migliavacca F, Guadagni G, Dubini G. Computational fluid dynamics in the evaluation of hemodynamic performance of cavopulmonary connections after the Norwood procedure for hypoplastic left heart syndrome. J Thorac Cardiovasc Surg. 2003;126:1040-7.

13. Hsia TY, Migliavacca F, Pittaccio S, Radaelli A, Dubini G, Pennati G, et al. Computational fluid dynamics study of flow optimization in realistic models of the total cavopulmonary connections. J Surg Res. 2004;116:305-13.

14. DeGroff C, Birnbaum B, Shandas R, Orlando W, Hertzberg J. Computational simulations of the total cavo-pulmonary connection: insights in optimizing numerical solutions. Med Eng Phys. 2005;27:135-46.

15. Pekkan K, Kitajima HD, de Zelicourt D, Forbess JM, Parks WJ, Fogel MA, Sharma S, Kanter KR, Frankes D, Yoganathan AP. Total cavopulmonary connection flow with functional left pulmonary artery stenosis: angioplasty and fenestration in vitro. Circulation. 2005;112:3264-71.

16. de Zélicourt D, Pekkan K, Parks J, Kanter K, Fogel M, Yoganathan AP. Flow study of an extracardiac connection with persistent left superior vena cava. J Thorac Cardiovasc Surg. 2006;131:785-91.

17. Whitehead KK, Pekkan K, Kitajima HD, Paridon SM, Yoganathan AP, Fogel MA. Nonlinear power loss during exercise in single-ventricle patients after the Fontan: insights from computational fluid dynamics. Circulation. 2007; 116(11 Suppl):I165-71. 
18. Marsden AL, Vignon-Clementel IE, Chan FP, Feinstein JA, Taylor CA. Effects of exercise and respiration on hemodynamic efficiency in CFD simulations of the total cavopulmonary connection. Ann Biomed Eng. 2007;35:250-63.

19. Itatani K, Miyaji K, Tomoyasu T, Nakahata Y, Ohara K, Takamoto S, et al. Optimal conduit size of the extracardiac Fontan operation based on energy loss and flow stagnation. Ann Thorac Surg. 2009;88:565-73.

20. Rosenthal M, Bush A, Deanfield J, Redington A. Comparison of cardiopulmonary adaptation during exercise in children after the atriopulmonary and total cavopulmonary connection Fontan procedures. Circulation. 1995;91:372-8.

21. Hjortdal VE, Emmertsen K, Stenbøg E, Fründ T, Schmidt MR, Kromann O, et al. Effects of exercise and respiration on blood flow in total cavopulmonary connection: a real-time magnetic resonance flow study. Circulation. 2003;108:1227-31.
22. Senzaki H, Isoda T, Ishizawa A, Hishi T. Reconsideration of criteria for the Fontan operation. Influence of pulmonary artery size on postoperative hemodynamics of the Fontan operation. Circulation. 1994;89:1196-202.

23. Dasi LP, Rema RK, Kitajima HD, Pekkan K, Sundareswaran KS, Fogel M, Sharma S, Whitehead K, Kanter K, Yoganathan AP. Fontan hemodynamics: importance of artery diameter. $J$ Thorac Cardiovasc Surg. 2009;137:560-4.

24. Salim MA, DiSessa TG, Arheart K, Alpert BS. Contribution of superior vena caval flow to total cardiac output in children. A Doppler echocardiographic study. Circulation. 1995;92:1860-5.

25. Vignon-Clementel IE, Figueroa CA, Jansen KE, Taylor CA. Outflow boundary conditions for three-dimensional finite element modeling of blood flow and pressure in arteries. Comput Methods App Mech Eng. 2006;195:3776-96. 